\title{
Characterization of Palladium Chelates and their Interactions with Z-N'-(benzo(d)thiazol-2-yl)-N,N-dimethylformimidamide using the Spectrophotometric and Computational Methods
}

\author{
AMR LOTFY SABER ${ }^{1,2 *}$, WAEL ABD-ALLAH ZORDOK ${ }^{1,3}$, \\ AHMED ALHARBI ${ }^{2}$ and ABDU SUBAIHI ${ }^{3}$ \\ ${ }^{1}$ Department of Chemistry, Faculty of Science, Zagazig University, Zagazig, Egypt. \\ ${ }^{2}$ Department of Chemistry, Faculty of Applied Science, Umm Al Qura University, Makkah, \\ Kingdom of Saudi Arabia. \\ ${ }^{3}$ Department of Chemistry, Al-Qunfidhah University College, Kingdom of Saudi Arabia. \\ ${ }^{*}$ Corresponding author E-mail: alshefny @yahoo.com \\ http://dx.doi.org/10.13005/ojc/350217
}

(Received: December 10, 2018; Accepted: March 24, 2019)

\begin{abstract}
A rapid, selective and sensitive method for the quantification of $\mathrm{Pd}$ (II) using spectrophotometric technique associated with Z-N'-(benzo(d)thiazol-2-yl)-N,N-dimethylformimidamide BTDF as new chelating agent is described. Yellow colored complex of Pd (II) with BTDF is formed in BrittonRobinson universal buffer of $\mathrm{pH} 9$ and extracted with chloroform. The formed complex clearly illustrate an absorption at $\sim 384 \mathrm{~nm}$ and follw Beer's law in the range of concentration between 0.5-18.0 $\mathrm{\mu g}$ $\mathrm{ml}^{-1}$ of Pd (II) with absorbance of $3.62 \times 10^{4} \mathrm{~L} \mathrm{~mol}^{-1} \mathrm{~cm}^{-1}$ and limit of detection (LOD) of Pd (II) 0.07 $\mu \mathrm{g} \mathrm{ml}^{-1}$. The effects of different experimental parameters have been established by study the optimum conditions for the extraction and quantification of palladium ion. Density functional theory (DFT) have also been employed to compute the influence of the cation on theoretical parameters of $\mathrm{Pd}^{2+}$ complexes. The effect of donating centers was investigated theoretically which prove that $\mathrm{Pd}^{2+}$ favor coordinated with two molecules of Z-N'-(benzo(d)thiazol-2-yl)-N,N-dimethylformimidamide through two nitrogen atoms. The performance of the examined method was estimated to detect the impact of current method over the presented methods in the literature without interference effect of cations and anions. The examined method has successfully demonstrated the quantification of $\mathrm{Pd}(\mathrm{II})$ in natural and spiked water samples.
\end{abstract}

Keywords: Spectrophotometry, Palladium ion, Dimethylformimidamide, DFT.

\section{INTRODUCTION}

Recently, the use of nitrogen containing heterocyclic derivatives in biological processes has attracted a lot of considerable attention, due to it snatural abundance, chemistry coordinating ability for a trace metal ion and promising application in industry ${ }^{1}$. The synthesis of platinum pyrimidine has

This is an Open Access article licensed under a Creative Commons license: Attribution 4.0 International (CC- BY). Published by Oriental Scientific Publishing Company @ 2018 
become an interesting complexes that can be isolated from the reaction of cisplatin with pyrimidines which have illustrated its effective for antitumor activity ${ }^{2-7}$. The ligand display a great versatility when interact with metal ion and strong coordinating unit, due to its influence on the electronic and steric properties of the central metal, interesting metal-metal interactions in some cases of compounds ${ }^{8}$. Depending on the conditions, reported study has indicated that pyrimidine ring is preferred binding to $\mathrm{Pd}(\mathrm{II})$ either in monodentate mode through one nitrogen atom commonly in a cis-configuration, or in bidentate mode through the two nitrogen atoms ${ }^{9}$.

Several studies have reported unprecedented compounds displayed new bonding modes for the pyrazolate ligands $\mathrm{Pd}(\mathrm{II})$ complexes ${ }^{10-14}$. Only few studies in the literature have been demonstrated the utilize of pyrazolyl derivative complexes for assembly or self-assembly in extended arrays ${ }^{15}$. Some derivatives of five-membered heterocycles have subjected to considerable attention in the literature ${ }^{16}$, in particular, studies on the synthesis of trifluoromethylsubstituted isoxazoles and pyrazoles ${ }^{17-19}$. In this work, the interactions of Z-N'-(benzo(d)thiazol2-yl)-N,N-dimethylformimidamide ligand with $\mathrm{Pd}(\mathrm{II})$ were investigated experimentally for the first time using a simple, easy to operate, reliable, highly sensitive and accurate extractive spectrophotometric method for the detection and quantification of $\mathrm{Pd}(\mathrm{II})$ in spiking different water samples and these interactions were approved using quantum chemical calculations by calculating the HOMO/LUMO energy values and bond angles, bond lengths, charge density and dihedral angles of the complexes.

\section{MATERIALS AND METHODS}

\section{Apparatus}

The spectra measurements for all samples were measured using a thermostatted Shimadzu UV-VIS-NIR-3600 double-beam spectrophotometer with wavelength range $150-1100 \mathrm{~nm}$, spectral bandwidth $2.0 \mathrm{~nm}$, with $10 \mathrm{~mm}$ matched quartz cells. The $\mathrm{pH}$ of solutions was tested using JENWAY Research Model $3510 \mathrm{pH}$ Meter.

\section{Reagents and solutions}

All of the chemicals utilized were of the highest purity analytical reagent grade. Double distilled water was utilized to prepare all the solutions.

(i) BTDF was synthesized based on the method described previously ${ }^{20}$. Standard stock solution $\left(0.01 \mathrm{moll}^{-1}\right)$ of Z-N'-(benzo(d)thiazol2-yl)-N,N-dimethylformimidamide(BTDF) was prepared by dissolving $0.205 \mathrm{~g}$ of BTDF with methanol in a $100 \mathrm{~mL}$ calibrated flask. All solutions were freshly prepared at lower concentrations by suitable dilution with methanol.

(ii) A stock solution $\left(0.01 \mathrm{~mol} \mathrm{~L}^{-1}\right)$ of palladium(II) chloride was prepared by dissolving 0.1773 $\mathrm{g}$ of anhydrous $\mathrm{PdCl}_{2}$ in $100 \mathrm{~mL}$ of water acidified with few drops of concentrated $\mathrm{HCl}$ then the obtained solution was standardized by EDTA method (Merck, 1982). Working solutions were prepared by suitable dilution of the stock solution with distilled water.

(iii) The standard methods ${ }^{21}$ were used to prepare different series of Britton-Robinson(B-R) universal buffer solutions.

\section{Recommended procedure}

An aliquot of sample containing $0.5-20$ $\mu \mathrm{g} \mathrm{mL}-1$ of $\mathrm{PdCl}_{2}$ solution in desired acidity was transferred into a series of $50 \mathrm{ml}$ separating funnels, $2.0 \mathrm{~mL}$ of $\left(1 \times 10^{-4} \mathrm{~mol} \mathrm{~L}^{-1}\right)$ BTDF was added and then the total volume of the aqueous phase was adjusted to $10 \mathrm{~mL}$ using buffer solution $\mathrm{pH} 9$ to give turbid yellowish solution of palladium complex then $10 \mathrm{~mL}$ of chloroform were added to each funnel and shaken process for the contents were done well for 5.0 minute. The two layers were allowed to separate and the organic phase was dried over anhydrous sodium sulphate. The absorbance spectra of the solution was measured against $\mathrm{BTDF} / \mathrm{CHCl}_{3}$ solution.

\section{Quantification of palladium ion in spiked and natural water samples}

Quantification of palladium (II) was performed in environmental samples that were previously checked negative for palladium (II). Then palladium (II) was spiked to tap water, lake and river samples at a concentration that obeyed the limitof Beer's law for the analysis. To remove suspended particulate substances from natural water samples spiked with palladium (II) a 0.45 $\mu$ mpore size membrane filter was used, after 
filtration the extraction efficiency for the recovery of palladium (II) was studied.The spectrophotometric measurements of final solution were carried out following the procedure mentioned above.

\section{RESULTS AND DISCUSSION}

Palladium ion forms metal complex in acidic medium ( $\mathrm{pH}$ 9) with Schiff base such as BTDF and this complex are extracted quantitatively into chloroform. The spectra of absorption of the yellow metal complex solution were detected in the range 300-550 nm against the blank solution (Fig. 2). The palladium complex shows the maximum absorbance at $\lambda_{\max }$ as provided in (Table 1).

Table 1: Effect of order of reactants addition

\begin{tabular}{ccc}
\hline S No. & Order of additiona & $\begin{array}{c}\text { Absorbance for } 1 \mathrm{ml} \\
\text { of } \mathrm{Pd}(\mathrm{II})\left(1.0 \times 10^{-4} \mathrm{M}\right)\end{array}$ \\
\hline 1 & $\mathrm{~A}+\mathrm{B}+\mathrm{C}$ & 0.42 \\
2 & $\mathrm{~A}+\mathrm{C}+\mathrm{B}$ & 0.4 \\
3 & $\mathrm{~B}+\mathrm{A}+\mathrm{C}$ & 0.4 \\
4 & $\mathrm{~B}+\mathrm{C}+\mathrm{A}$ & 0.41 \\
5 & $\mathrm{C}+\mathrm{A}+\mathrm{B}$ & 0.42 \\
6 & $\mathrm{C}+\mathrm{B}+\mathrm{A}$ & 0.42 \\
\hline
\end{tabular}

$\mathrm{aA}=\mathrm{BTDF}, \mathrm{B}=$ palladium $(\mathrm{II}), \mathrm{C}=$ Buffer solution

\section{Spectral characteristics}

In the current method a yellow colored of the extracted solution was formed with minimal interference, it was necessary to carry out the optimization to achieve the optimum wavelength for palladium(II) quantification. This wavelength should be specific monitoring and specific for Pd-BTDF quantification. The wavelength of maximum absorbance was obtained by measuring the yellow colored solution within the range $300-550 \mathrm{~nm}$ with various concentrations of palladium(III).

The optimum wavelength for achieving the best results was generated to be $384 \mathrm{~nm}$ and the reagent blanks had negligible absorption at the same wavelength. The absorption spectra of the metal complex is presented in Figure 1.

\section{Optimum reagents concentrations}

The BTDF effect was examined by using a constant palladium(II) concentration in $10 \mathrm{~mL}$ standard flask. It was observed that $\left(1 \times 10^{-4} \mathrm{~mol} \mathrm{~L}^{-1}\right)$ BTDF in the range of $0.5-3.0 \mathrm{~mL}$ was adequate to obtain the yellow color. Hence, $2.0 \mathrm{~mL}$ of $\left(1 \times 10^{-4}\right.$ $\left.\mathrm{mol} \mathrm{L}^{-1}\right) \mathrm{BTDF}$ was preferred to achieve the maximum color intensity and utilized for further studies. Excellent data wasgenerated when distilled water used for dilution and chloroform for extraction of the color product show more better than the other solvents.

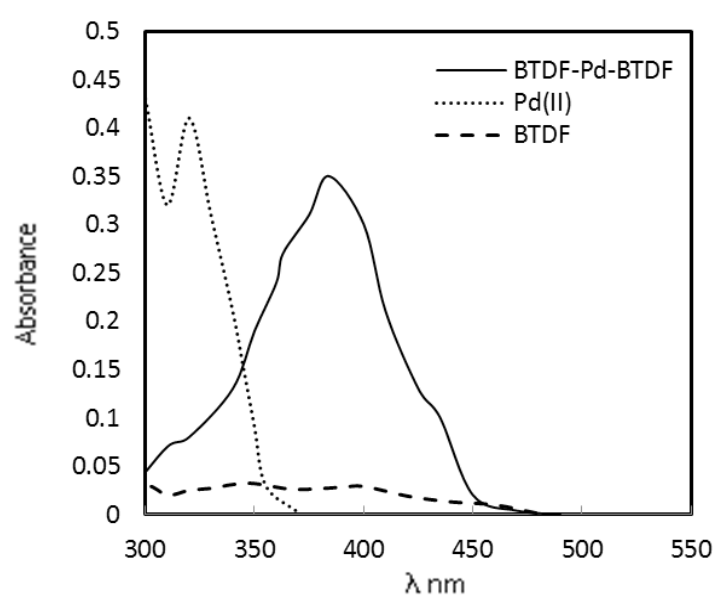

Fig. 1. Absorption spectra of (.....) Pd (-----) BTDF and ( $\square$ ) the complex of BTDF-Pd-BTDF in the range of $300-550 \mathrm{~nm}$

The sensitivity of the proposed method increasedby increasing BTDF volume up to $2.0 \mathrm{~mL}$ of $\left(1 \times 10^{-4} \mathrm{~mol} \mathrm{~L}^{-1}\right)$ and decreased at higher volume due to this fact that the free BTDF competes with the complexes inextraction rich phase.

\section{Effect of $\mathrm{pH}$}

The effect of $\mathrm{pH}$ on the formation of palladium (II)-BTDF complex and its absorbance was investigated by mixing $1.0 \mathrm{~mL}\left(1 \times 10^{-4} \mathrm{M}\right)$ palladium (II), $2.0 \mathrm{~mL}\left(1 \times 10^{-4} \mathrm{M}\right)$ BTDF and $5.0 \mathrm{~mL} \mathrm{pH} 2$ - 12 of universal buffer. The mixture was diluted to volume mark in a $10 \mathrm{~mL}$ standard flask with dist. water then the absorbance of the extracted yellow color complex was measured.

By comparing different types of buffer solution, the universal bufferillu strated the highest selectivity, sensitivity, stability and linearityof yellow colored product while the blank remained colorless in chloroform presence. The absorbance was maximum at pH 9.0 which was selected as optimal (Figure 2).

\section{Choice of organic solvent}

A different organic solvents such as chloroform, dichloromethane, carbon tetrachloride, toluene, and benzene were tested for extraction 
of Pd-BTDF complex using applicable extraction procedure. The best appropriate solvent for the extraction of yellow colored complexes was chloroform that yielding maximum absorbance intensity.

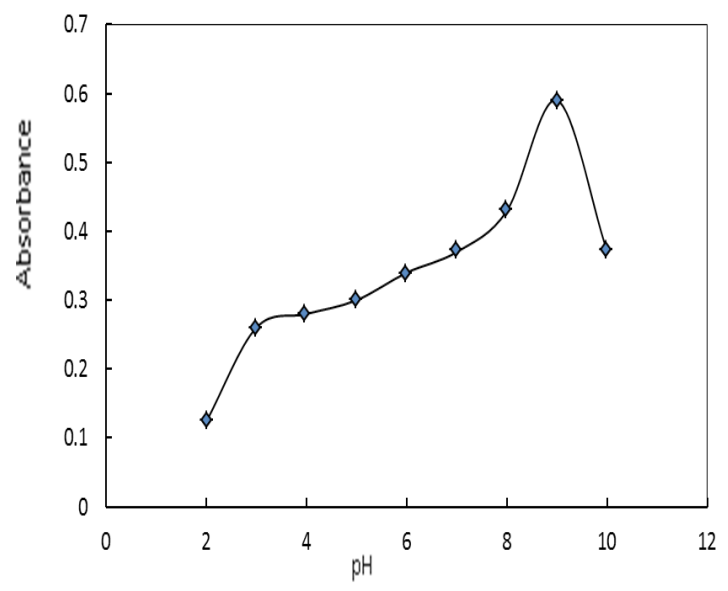

Fig. 2. Effect of pH of universal buffer on the color intensity of the complex

Table 2: Optical parameters for the determination of palladium(II)

\begin{tabular}{|c|c|}
\hline Parameter & Characteristic \\
\hline $\mathrm{pH}$ & 9 \\
\hline Extracting solvent & chloroform \\
\hline$\lambda_{\max }$ & 384 \\
\hline Molar ratio (Pd-BTDF) & $1: 2$ \\
\hline Beer,s law limits $\left(\mu \mathrm{g} \mathrm{mL}^{-1}\right)$ & $0.5-18.0$ \\
\hline Molar absorptivity $\left(\mathrm{I} \mathrm{mol}^{-1} \mathrm{~cm}^{-1}\right)$ & $3.62 \times 104$ \\
\hline Sandell,s sensitivity $\left(\mathrm{ng} \mathrm{cm}^{-2}\right.$ ) & 17.2 \\
\hline \multicolumn{2}{|l|}{ Regression equation* } \\
\hline Intercept & 0.07 \\
\hline Slope & 0.058 \\
\hline Correlation coefficient ( $r$ ) & 0.9994 \\
\hline Range of error $\%$ & $-0.48: 0.61$ \\
\hline pK & 6.13 \\
\hline Detection limit LOD $\left(\mu \mathrm{g} \mathrm{ml}^{-1}\right)$ & 0.053 \\
\hline Quantification limit LOQ $\left(\mu \mathrm{g} \mathrm{ml}^{-1}\right)$ & 0.16 \\
\hline
\end{tabular}

\section{Order of reactants addition}

The influence of order of reactants addition was investigated by using varies orders of the reactants in optimized amounts. The data obtained has demonstrated that, the order of addition of reactants unaffected on the absorbance values as provided in Table 2, but for maintaining the similarity of the order of addition of reactants, series No.1 of Table 1 was followed throughout course of the quantification of palladium(II).
Effect of time and temperature on color stability

In light of the optimized conditions, in spite of the color developed instantaneously, five minutes were adequate to get the constant and maximum absorbance, the colored complex was stable for one day. The measurements of absorbance changed by not more than $5 \%$ over a period of $30 \mathrm{~h}$ and the color formation was independent of temperature in the range of $10-45^{\circ} \mathrm{C}$. Hence, five minutes reaction at ambient temperature was adequate for the analysis.

\section{Composition of complex}

Stoichiometric ratio of BTDF to $\mathrm{PdCl}_{2}$ in the complex was observed by the Job's method of continuous variation using variable BTDF and palladium ion concentrations. The results showed that the stoichiometric ratio was 1:2 (Pd-BTDF) at the optimum conditions

\section{Analytical application}

The determination of palladium was occurred using the proposed method by spiked water samples with known quantity of palladium(II) and study the recovery. The data generated by the current method was definite by measurements of palladiun contents using the reported methods ${ }^{22}$. Student, s t-test and the variance ratio F-test at 95\% confidence level were calculated and showed that the calculationsdid not override those the oreticalvalues. Table 3 showed that there is no significant difference between those measured by proposed method and the spiked quantities and from the previous methods, referring that the current method is as accurate and precise as the previous methods. The comparison between the proposed method and some different reported methods has shown that, the proposed method is rapid, simple, and highly sensitive than the semethods in survey provided in Table 4.

\section{Computational details}

Density functional theory (DFT) was utilized to study of the cation effect on theoretical parameters of the $\mathrm{Pd}^{2+}$ complexes of Z-N'-(benzo(d)thiazol-2-yl)$\mathrm{N}, \mathrm{N}$-dimethylformimidamide and detect the exact structure of the complex results from coordination with metal ion. The Z-N'-(benzo(d)thiazol-2-yl)-N,Ndimethylformimidamide compound has posses four donating centers, three nitrogen atoms and one sulpher atom. The divalent metal ion $\mathrm{Pd}^{2+}$ may be chelated with two nitrogen atoms or chelated through the one nitrogen atom and one sulpher atom, so in 
this part we study the two complexes results from the two modes of chelation and show which is more stable than other. The pronounced effect of donating centers was examined theoretically and the excited state for entire compounds was investigated to establish the different types of electronic transitions which can be occurred on these compounds with different structure. The Frontier molecular orbitals were studied for its important role in the optical and electric characteristics, as well as in chemical reactions and UV-Vis. spectra. Profiles of the geometry and optimal set of these complexes were studied using the GAUSSIAN 98W package of programs $^{23}$ at Cep-31G level of theory ${ }^{24}$.

Table 3: Determination of palladium (II) in different water samples

\begin{tabular}{|c|c|c|c|c|c|c|c|}
\hline \multirow[t]{2}{*}{ Samples } & $\mathrm{m}$ added $\mu \mathrm{g} \mathrm{ml}^{-1}$ & \multicolumn{4}{|c|}{ Palladium found $\left(\mu \mathrm{g} \mathrm{ml}^{-1}\right)$} & \multicolumn{2}{|c|}{ t-test ${ }^{b} F$-test ${ }^{c}$} \\
\hline & & \multicolumn{2}{|c|}{$\begin{array}{l}\text { Proposed method } \\
\text { Found }{ }^{a} \text { Recovery }\end{array}$} & \multicolumn{2}{|c|}{$\begin{array}{l}\text { Reported method } \\
\text { Founda Recovery }\end{array}$} & & \\
\hline Drinking water & 0.5 & $0.49 \pm 1.20$ & 98.0 & $0.503 \pm 1.45$ & 100.6 & 0.94 & 1.83 \\
\hline \multirow[t]{2}{*}{$(\mathrm{Al}$ Qassim-KSA*) } & 2 & $1.98 \pm 0.48$ & 99.0 & $2.007 \pm 0.65$ & 100.3 & 0.96 & 1.07 \\
\hline & 4 & $4.02 \pm 0.55$ & 100.5 & $3.994 \pm 0.29$ & 99.8 & 0.44 & 1.57 \\
\hline Tab water & & $0.498 \pm 1.26$ & 99.6 & $0.504 \pm 1.66$ & 100.8 & & \\
\hline \multirow[t]{3}{*}{$($ Al Azizea-Makkah-KSA*) } & 0.5 & $2.006 \pm 0.57$ & 100.3 & $2.004 \pm 0.44$ & 100.2 & 1.28 & 1.85 \\
\hline & 2 & $3.986 \pm 0.54$ & 99.7 & $3.997 \pm 0.52$ & 99.9 & 0.80 & 2.13 \\
\hline & 4 & & & & & 1.18 & 1.79 \\
\hline \multicolumn{8}{|l|}{ Tab water } \\
\hline \multirow[t]{4}{*}{$\left(\right.$ Alabdia-Makkah-KSA $\left.{ }^{\star}\right)$} & & $0.492 \pm 1.36$ & 98.4 & $0.504 \pm 1.87$ & 100.8 & & \\
\hline & 0.5 & $1.964 \pm 0.44$ & 98.2 & $1.994 \pm 0.47$ & 99.7 & \multicolumn{2}{|c|}{1.281 .88} \\
\hline & 2 & $3.992 \pm 0.33$ & 99.8 & $3.991 \pm 0.58$ & 99.7 & 0.42 & 1.86 \\
\hline & 4 & & & & & \multicolumn{2}{|c|}{0.761 .58} \\
\hline
\end{tabular}

a Mean \pm Relative Standard Deviation $(n=5) ;$, c Values in parentheses are the theoretical values for $t-$ and $F-$ values at $95 \%$ confidencelimits and five degrees of freedom; * Kingdom of Saudi Arabia.

Table 4: Comparison of recommended method with reported methods

\begin{tabular}{|c|c|c|c|c|}
\hline Reagent & $\lambda_{\max }(\mathrm{nm})$ & $\begin{array}{l}\text { Molar absorptivity, } \\
\qquad \mathrm{I} \mathrm{mol}^{-1} \mathrm{~cm}^{-1}\end{array}$ & Conditions & Ref. \\
\hline $\begin{array}{l}\text {-Pyridoxal-4-phenyl-3-thiosemicarbazone. } \\
\text {-Benzyloxybenzaldehyd }\end{array}$ & 460 & $2.2 \times 10^{4}$ & Benzene, pH 3.0 & {$[53]$} \\
\hline $\begin{array}{l}\text { ethiosemicarbazone. } \\
\text {-N-ethyl-3-carbazolecarbax }\end{array}$ & 365 & $0.4 \times 10^{4}$ & Cyclohexanol, pH 5 & {$[54]$} \\
\hline $\begin{array}{l}\text { aledehyde-thiosemicarbazone. } \\
\text {-Benzoin oxime. }\end{array}$ & 410 & $1.6 \times 10^{4}$ & n-butanol, pH 4.0 & {$[55]$} \\
\hline \multirow[t]{2}{*}{$\begin{array}{l}\text {-2-(2-Quinolylazo)-5- } \\
\text { dimethylaminoaniline }\end{array}$} & 330 & $4.0 \times 10^{3}$ & Hexone, $1 \mathrm{M} \mathrm{HNO} 3$ & {$[56]$} \\
\hline & 600 & $13.5 \times 10^{4}$ & In $0.5-2.5 \mathrm{M} \mathrm{HCl}$ & {$[57]$} \\
\hline $\begin{array}{l}\text {-N-Dodecyl-N0-(sodium-p-aminobenzenest } \\
\text { thiourea } \\
\text { BTDF }\end{array}$ & 296 & $7.41 \times 10^{4}$ & In CTMAB andNaAc-HAc buffer & {$[58]$} \\
\hline & 384 & $3.62 \times 10^{4}$ & Chloroform, pH 9.0 & Present work \\
\hline
\end{tabular}

\section{Computational method}

The geometric and energies parameters were studied at the B3LYP/Cep-31G level of theory by DFT, appling the GAUSSIAN 98W package of the programs, on geometries that were examined at Cep-31G basis set. The atomic charges were studied by the natural atomic orbital populations. The B3LYP is important for the hybrid functional ${ }^{25}$, which shows a linear combination by Becke of the gradient functionals reported ${ }^{26}$, Yang, Lee and Parr ${ }^{27}$, together with local exchange function by Hartree-Fock ${ }^{28}$.

\section{Model of compounds and structural parameters Z-N'-(benzo(d)thiazol-2-yl)-N,N-dimethylformimid amide}

The chelating effect of this compound is 
mainly detected by its structure, the Z-N'-(benzo(d) thiazol-2-yl)-N,N-dimethylformimidamide has many characteristic structural features. The molecule is completely planer, also it is considered not highly sterically-hindered, there are two aromatic rings. The bond length C1-N3 is $1.369 \AA$, N2-C6 is 1.374 $\AA$, also the C6-N7 is $1.317 \AA$ there is a double bond characters $\mathrm{C}$ and $\mathrm{N}$ atoms ${ }^{29}$, whereas $\mathrm{C} 1-\mathrm{N} 2$ is double bond $1.316 \AA^{30}$. Analysis of investigated bond lengths in different sulfa molecules was given elsewhere ${ }^{31}$. All distances and angles between the atoms of the sulfa compound system are given in Table (1). The S8-C10 and C6-S8 bond lengths are $1.788 \AA$ and $1.796 \AA^{32}$ respectively, the N3-C4 and N3-C5 bond lengths are $1.423 \AA^{33}$, also the N7-C9 bond length is $1.401 \AA^{33}$.

The molecule is a completely planer and not highly sterically-hindered as seen in Fig.(3), the Z-N'(benzo(d)thiazol-2-yl)-N,N-dimethylformimidamide compound occupied one plan and all fragments are laying in the same plane, the dihedral angle C4N3C1N2, $179.99^{\circ}$ and C5N3C1N2, $-0.00^{\circ}$, it is means that the two terminal methyl groups are in the plane of central aromatic ring. The values of calculated dihedral angles: N3C1N2C6, 179.90', C1N2C6N7 and C1N2C6S8 are $-179.90^{\circ}$ and $0.00^{\circ}$ respectively, so the aromatic ring lying in the plane of the molecule. Fig.(3), shows the optimized geometrical structure of Z-N'-(benzo(d)thiazol-2-yl)$\mathrm{N}, \mathrm{N}$-dimethylformimidamide compound, the dihedral angles $\mathrm{N} 2 \mathrm{C} 6 \mathrm{~N} 7 \mathrm{C} 9$ is $179.90^{\circ}$ and $\mathrm{N} 2 \mathrm{C} 6 \mathrm{~S} 8 \mathrm{C} 10$ is $-179.90^{\circ}$ which confirms that the $\mathrm{N} 2$ and $\mathrm{C} 1$ lying in the same plane occupied by the two terminal methyl groups and lying in the same plane of the central aromatic ring.

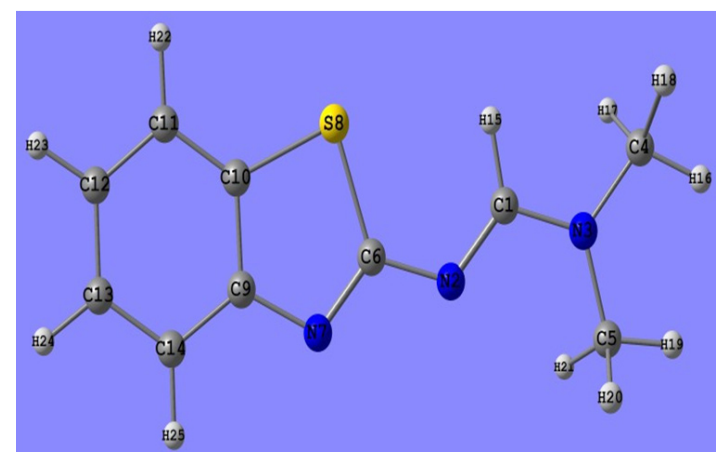

Fig. 3. The optimized geometrical structure of Z-N'-(benzo(d)thiazol-2-yl)-N,N-dimethylformimidamide compound by using B3LYP/Cep-31G
The optimized geometrical parameters, bond distances, bond angles and dihedral angles of Z-N'(benzo(d)thiazol-2-yl)-N,N-dimethylformimidamide as obtained from $B_{3}$ LYP/Cep-31G calculations are listed in Table (5). These data are drowning to give the optimized geometry of molecule as shown in Fig. (3). The bond angles, C4N3C5 is $121.22^{\circ}, \mathrm{C} 1 \mathrm{~N} 3 \mathrm{C} 5$ is $120.08^{\circ}, \mathrm{C} 1 \mathrm{~N} 3 \mathrm{C} 4$ is $118.69^{\circ}$ and $\mathrm{N} 2 \mathrm{C} 1 \mathrm{~N} 3$ is $119.79^{\circ}$ and $\mathrm{C} 1 \mathrm{~N} 2 \mathrm{C} 6$ is $120.34^{\circ}$ reflects on $\mathrm{sp}^{2}$ hybridization of the N3 atom. The values of bond distances are compared nicely with that obtained from X-ray data ${ }^{29}$. Comparisons of the performance of varies DFT procedures allow outlining the principle trends of these theoretical approaches which are necessary to better understand reaction mechanisms of Z-N'(benzo(d)thiazol-2-yl)-N,N-dimethylformimidamide compound and the properties. However, till now, no attempt has been made to analyze the application of different DFT steps and various basis sets for accurate calculations of structure of Z-N'-(benzo(d) thiazol-2-yl)-N,N-dimethylformimidamide ${ }^{33}$.

The accumulated charge on S8 (-0.329), C6 (0.387) and C10 (0.097), reflects that the $S$ atom is bonded strongly with surrounded two carbon atoms. The presence of thiazole ring attached to the benzene ring effects on the charge spreading overall the compound, also the charges on the two terminal methyl group are effected by attached with nitrogen atom, the charge on C4 $(-0.043)$ and C5 $(-0.034)$. The energy of this compound is -114.844553978 au and very lower value of dipole 3.52D.

$\mathrm{Pd}^{2+}$ complex with Z-N'-(benzo(d)thiazol-2yl)-N,N-dimethylformimidamide through the nitrogen and sulpher atoms

In this complex, there are three plans one occupied by two terminal ends of the ligand bonded with $\mathrm{Pd}^{2+}$ through the nitrogen atoms of amino group and this plane is lying between others two planes occupied by two aromatic rings of the two ligand molecules as shown in Fig.(4). All parameters, selected inter atomic distances and angles of the complex are listed in Table (6). The complex is four-coordinate, the metal ion $\mathrm{Pd}^{2+}$ is coordinated to two unites of Z-N'-(benzo(d)thiazol-2-yl)-N,Ndimethylformimidamide molecules, one $\mathrm{N}$-amino 
group and one S-thiazole ring of one Z-N'-(benzo(d) thiazol-2-yl)-N,N-dimethylformimidamide ligand. The $\mathrm{Pd}-\mathrm{S}$ bond lengths $(2.28 \AA \AA \text { and } 2.27 \AA)^{34}$ are longer than the Pd-N (1.98 $\AA$ and $1.99 \AA)^{35,36}$. The angles around central metal ion $\mathrm{Pd}^{2+}$ with surrounded four donating atoms of the two molecules of Z-N'(benzo(d)thiazol-2-yl)-N,N-dimethylformimidamide vary from $97.90^{\circ}$ to $119.21^{\circ}$, these values not deviated slightly from these expected for tetrahedral structure $^{37}$. The distances between Pd-S and Pd-N and angles around the central metal ion are given in Table (6), these values are in agreement with experimental data ${ }^{38}$.

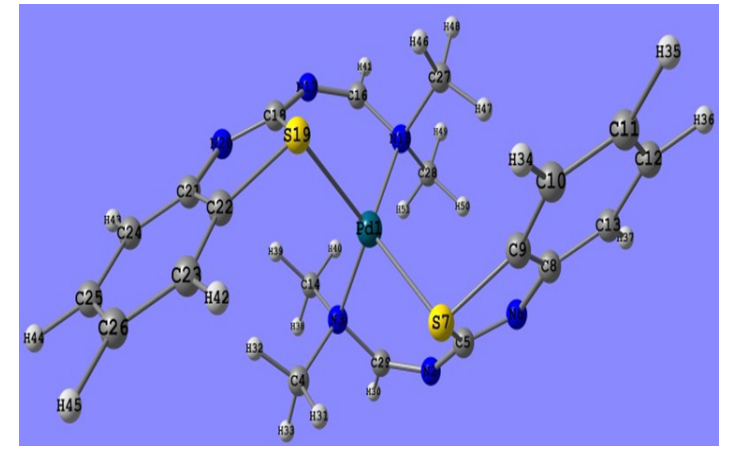

Fig. 4. Optimized geometrical structure of $\mathrm{Pd}^{2+}$ complex with Z-N'-(benzo(d)thiazol-2-yl)-N,N-dimethylformimidamide through sulpher and nitrogen atoms by using B3LYP/Cep-31G

Table 5: Equilibrium geometric parameters bond lengths $(\AA)$, bond angles $\left({ }^{\circ}\right)$, dihedral angles $\left({ }^{\circ}\right)$ and charge density of Z-N'-(benzo(d)thiazol-2-yl)-N,N-dimethylformimidamide compound by using DFT/ B3LYP/Cep-31G

\begin{tabular}{|c|c|c|c|c|c|c|c|}
\hline \multicolumn{8}{|c|}{ Bond length $(\AA)$} \\
\hline $\mathrm{C} 1-\mathrm{N} 2$ & 1.316 & C1-N3 & 1.369 & N3-C4 & 1.423 & N3-C5 & 1.423 \\
\hline $\mathrm{N} 2-\mathrm{C} 6$ & 1.374 & C6-N7 & 1.317 & N7-C9 & 1.401 & C9-C10 & 1.412 \\
\hline S8-C10 1 & 1.788 & C6-S8 & 1.796 & C10-C11 & 1.387 & C11-C12 & 1.396 \\
\hline C9-C14 1. & 1.398 & C13-C14 & 1.393 & C12-C13 & 1.395 & & \\
\hline \multicolumn{8}{|c|}{ Bond angle $\left({ }^{\circ}\right)$} \\
\hline C4N3C5 & 121.22 & $\mathrm{C} 1 \mathrm{~N} 2 \mathrm{C} 6$ & 120.34 & C6S8C10 & 87.96 & $\mathrm{C} 1 \mathrm{~N} 3 \mathrm{C} 4$ & 118.69 \\
\hline N2C6N7 & 120.39 & S8C10C9 & 108.95 & C1N3C5 & 120.08 & $\mathrm{~N} 2 \mathrm{C} 6 \mathrm{~S} 8$ & 123.37 \\
\hline N7C9C10 & 116.47 & N3C1N2 & 119.79 & N7C6S8 & 116.23 & C12C13C14 & 121.12 \\
\hline N7C9C14 & 124.65 & S8C10C11 & 128.24 & C10C11C12 & 117.08 & C11C12C13 & 121.27 \\
\hline C9N7C6 & 110.39 & C9C10C11 & 122.81 & C13C14C9 & 118.84 & C10C9C14 & 118.88 \\
\hline \multicolumn{8}{|c|}{ Dihedral angles $\left({ }^{\circ}\right)$} \\
\hline $\mathrm{C} 4 \mathrm{~N} 3 \mathrm{C} 1 \mathrm{~N} 2$ & $2 \quad 179.99$ & C1N2C6S8 & 0.00 & C6N7C9C10 & 0.00 & & \\
\hline C5N3C1N2 & $2-0.00$ & N2C6S8C10 & -179.90 & S8C $10 C 9 C 14$ & 180.00 & & \\
\hline N3C1N2C6 & $\begin{array}{ll}6 & 179.90\end{array}$ & N2C6N7C9 & 179.90 & $\mathrm{~S} 8 \mathrm{C} 10 \mathrm{C} 11 \mathrm{C} 12$ & -179.00 & & \\
\hline \multirow{2}{*}{ C1N2C6N7 } & $7 \quad-179.90$ & C6N7C9C14 & 179.90 & N7C9C14C13 & -179.00 & & \\
\hline & & & & N7C $9 \mathrm{C} 10 \mathrm{C} 11$ & -179.90 & & \\
\hline \multicolumn{8}{|l|}{ Charges } \\
\hline $\mathrm{C} 1$ & 0.247 & N2 & -0.323 & N3 & 0.095 & $\mathrm{C} 4$ & -0.043 \\
\hline C5 & 0.034 & C6 & 0.387 & N7 & 0.306 & S8 & -0.329 \\
\hline & 0.126 & C10 & 0.097 & & & & \\
\hline \multirow{2}{*}{\multicolumn{4}{|c|}{$\begin{array}{l}\text { Total energy/au } \\
\text { Total dipole moment/D }\end{array}$}} & \multirow{2}{*}{\multicolumn{2}{|c|}{$\begin{array}{c}-114.844554 \\
3.52\end{array}$}} & & \\
\hline & & & & & & & \\
\hline
\end{tabular}

The complex is a highly sterically-hindered, the two units of Z-N'-(benzo(d)thiazol-2-yl)-N,Ndimethylformimidamide with $\mathrm{Pd}^{2+}$ in this complx occupied three plans they are not perpendicular to each other. This result can be confirmed from the values of the dihedral angle N15PdN3C29,79.09 and N15PdS7C5, $-65.74^{\circ}$, where the values are neither zero nor $180^{\circ}$, so the terminal end of the two amino groups bonded with metal ion not axially oriented from the ring and then out of plane occupied by other two aromatic rings. Also the two aromatic rings lying out of the plane occupied by metal ion bonded with terminal two amino groups, this observation is supported by the values of calculated dihedral angles: S19PdS7C5, $-176.56^{\circ}$ and S19PdN3C29, $-165.07^{\circ}$. Fig.(4), reveals the optimized geometrical structure of Pd2+-Z-N'-(benzo(d)thiazol-2-yl)-N,Ndimethylformimidamide.

The charge accumulated on S7 and S19 are $(-0.115$ and -0.118 respectively) also, N3 and $\mathrm{N} 15$ are (0.027 and 0.009 respectively). The charge accumulated in N2 (-0.200) and N17 (-0.206) also the charge accumulated on carbon atoms, $\mathrm{C} 5$ and C29 are (-0.052 and 0.255) while C16 and C18 are (0.258 and 0.407) as shown in Table (6). The energy of this complex is -259.906935547 au and dipole moment is $6.125 \mathrm{D}$. 
$\mathrm{Pd}^{2+}$ complex with Z-N'-(benzo(d)thiazol-2-yl)-N,Ndimethylformimidamide through two nitrogen atoms

The $\mathrm{Pd}^{2+}$ ion, at a crystallographic inversion center, is in a tetrahedral environment. In the axial plane the metal ion is coordinated by two nitrogen atoms (N-amino and $\mathrm{N}$-thiazole) of two Z-N'(benzo(d)thiazol-2-yl)-N,N-dimethylformimidamide ligands at the distances vary from $1.941 \AA$ to $1.976 \AA$, these bond lengths are similar to those observed in related compounds ${ }^{39}$. Fig.(5) reveals the optimized geometrical structure of the complex of $\mathrm{Pd}^{2+}$ with Z-N'-(benzo(d)thiazol-2-yl)-N,Ndimethylformimidamide through two nitrogen atoms with the atomic numbering scheme selected bond distances and angles are given in Table (7). The difference in the C18-N19 and C6-N8 (1.272 $\AA$ and $1.271 \AA$ ) compared with the C6-N7 in the free ligand $(1.317 \AA)^{40}$, confirms the formation of bond between the nitrogen atom of thiazole ring and $\mathrm{Pd}^{2+}$ ion; these bond lengths are virtually identical in uncomplexed Z-N'-(benzo(d)thiazol-2-yl)-N,Ndimethylformimidamide ligand. The tetrahedral coordination environment is detected from the values of angles around the $\mathrm{Pd}^{2+}$ in complex as given in Table (7). The bond distance between $\mathrm{Pd}-\mathrm{N} 3$ is $1.976 \AA$ and Pd-N8 is $1.942 \AA^{35}$ while the distance between Pd-N15 is $1.975 \AA$ and $\mathrm{Pd}-\mathrm{N} 19$ is $1.941 \AA$ [36]. The Pd-N3 and Pd-N15 bond lengths are longer than that $\mathrm{Pd}-\mathrm{N} 8$ and $\mathrm{Pd}-\mathrm{N} 19$. The bond angles around the central metal ion Pd vary from $98.94^{\circ}$ to $120.95^{\circ}$; these values not differ significantly from these expected for tetrahedral structure. The energy of this complex is -260.013457522 au and the dipole moment is high $3.781 \mathrm{D}$, so this complex is considered more stable.

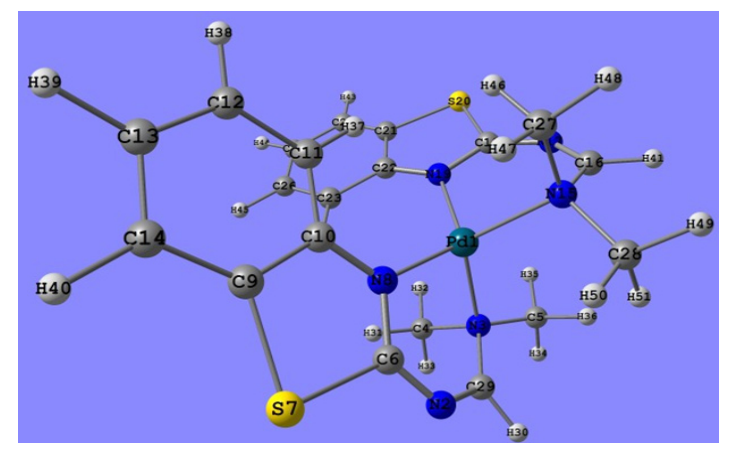

Fig. 5. Optimized geometrical structure of $\mathrm{Pd}^{2+}$ complex with Z-N'-(benzo(d)thiazol-2-yl)-N,N-dimethylformimidamide through two nitrogen atoms by using B3LYP/Cep-31G

Table 6: Equilibrium geometric parameters bond lengths $(\AA \AA)$, bond angles $\left({ }^{\circ}\right)$, dihedral angles $\left({ }^{\circ}\right)$ and charge density of the first complex by using DFT/B3LYP/Cep-31G

\begin{tabular}{|c|c|c|c|c|c|c|c|c|}
\hline \multicolumn{9}{|c|}{ Bond length $(\AA)$} \\
\hline Pd-S7 & 2.28 & & Pd-N3 & 1.98 & Pd-S19 & 2.27 & Pd-N15 & 1.99 \\
\hline C5-S7 & 1.76 & & C5-N2 & 1.26 & N2-C29 & 1.27 & N3-C29 & 1.39 \\
\hline $\mathrm{N} 15-\mathrm{C} 16$ & 1.39 & & C16-N17 & 1.26 & C18-N17 & 1.26 & C18-S19 & 1.76 \\
\hline C5-S7 & 1.76 & & C5-N2 & 1.26 & N2-C29 & 1.27 & N3-C29 & 1.39 \\
\hline \multicolumn{9}{|c|}{ Bond angle $\left({ }^{\circ}\right)$} \\
\hline \multicolumn{3}{|c|}{ N15-Pd-S19 } & 97.90 & N15-Pd-N3 & 115.08 & & N15-Pd-S7 & 119.21 \\
\hline \multicolumn{3}{|c|}{ N3-Pd-S19 } & 119.21 & S7-Pd-S19 & 108.70 & & N3-Pd-S7 & 97.91 \\
\hline \multicolumn{9}{|c|}{ Dihedral angles $\left({ }^{\circ}\right)$} \\
\hline \multicolumn{2}{|c|}{ N15-Pd-N3-C29 } & 79.09 & N15-Pd-S7-C5 & -65.74 & S19-Pd-S7-C5 & -176.56 & & \\
\hline \multicolumn{2}{|c|}{ S19-Pd-N3-C29 } & -165.07 & N3-Pd-N15C16 & 79.08 & N3-Pd-S19-C18 & -65.73 & & \\
\hline \multicolumn{2}{|c|}{ S7-Pd-S19-C18 } & -176.56 & S7-Pd-N15-C16 & -165.08 & & & & \\
\hline \multicolumn{9}{|l|}{ Charges } \\
\hline $\mathrm{Pd}$ & \multicolumn{2}{|l|}{1.030} & $\mathrm{~N} 2$ & -0.234 & N3 & 0.018 & C5 & 0.429 \\
\hline S7 & \multicolumn{2}{|l|}{-0.068} & $\mathrm{C} 29$ & 0.281 & N15 & 0.018 & $\mathrm{~N} 17$ & -0.234 \\
\hline C16 & \multicolumn{2}{|l|}{0.281} & C18 & 0.429 & S19 & -0.068 & & \\
\hline \multicolumn{3}{|c|}{ Total energy/au } & & & \multicolumn{2}{|c|}{-259.9069355} & & \\
\hline \multicolumn{3}{|c|}{ Total dipole moment/D } & & & \multicolumn{2}{|c|}{2.754} & & \\
\hline
\end{tabular}


Table 7: Equilibrium geometric parameters bond lengths $(\AA)$, bond angles $\left({ }^{\circ}\right)$, dihedral angles $\left({ }^{\circ}\right)$ and charge density of the second complex by using DFT/B3LYP/Cep-31G

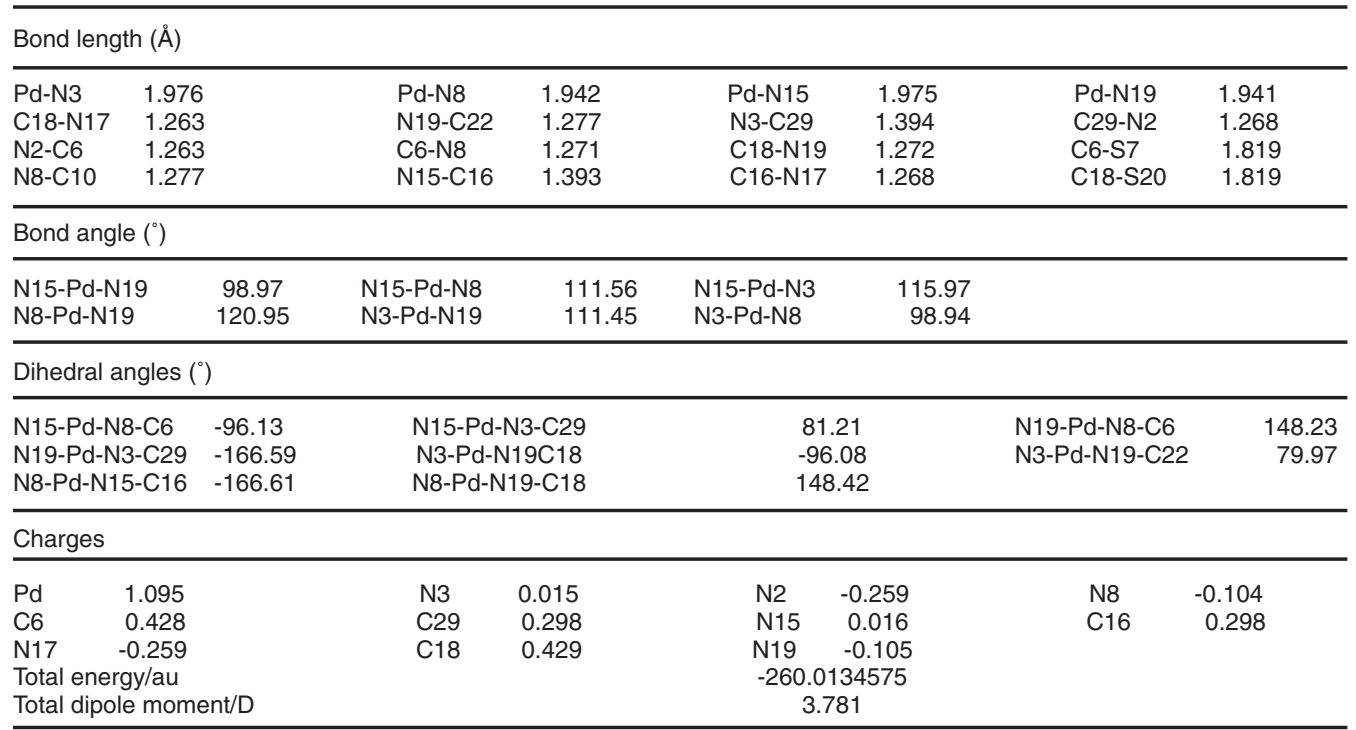

The bond distances between $\mathrm{Pd}^{2+}$ and surrounded nitrogen atoms of Z-N'-(benzo(d)thiazol2-yl)-N,N-dimethylformimidamide in tetrahedral complex are shorter than that in other complex as shown in Tables (6 and 7). Also the charge accumulated on N-amino group, N3 and N15 are $(0.015$ and 0.016$)$ and $\mathrm{N}$-thiazole ring, N8 and N19 are (-0.104 and -0.105$)$, in case of bonding of central metal ion with Z-N'-(benzo(d)thiazol-2-yl)-N,Ndimethylformimidamide through two nitrogen atoms. In case of other complex when Z-N'-(benzo(d)thiazol2-yl)-N,N-dimethylformimidamide bonded with $\mathrm{Pd}^{2+}$ through sulpher atom of thiazole and one nitrogen atom of amino group,the charge on $\mathrm{N}$-amino group, $\mathrm{N} 3$ and N15 are (0.017 and 0.019) and charge on S-thiazole S7 and S19 are -0.068 . These values are indicating that there is a strong interaction between central metal ion $\mathrm{Pd}^{2+}$ which has charge equal +1.095 and more negative nitrogen atoms in second complex greater than that in first complex, at which $\mathrm{Pd}^{2+}$ has less positively charge $(+1.03)$ in first complex. The energy of the second complex is more negative than that in the first complex, moreover the dipole moment is high and the bond distances between the $\mathrm{Pd}^{2+}$ and surrounded four nitrogen atoms in the second complex are shorter than that in the first complex. These reasons have confirmed that the second tetrahedral complex is more stable than the first tetrahedral complex and $\mathrm{Pd}^{2+}$ prefer coordinated with two molecules of Z-N'-(benzo(d) thiazol-2-yl)-N,N-dimethylformimidamide through two nitrogen atoms.

\section{Frontier molecular orbitals}

The frontier molecular orbitals play also an essential role in the UV-Vis. Spectra ${ }^{41}$. Fig. 6, illustrates the distributions and energy levels of $\mathrm{HOMO}$ and
LUMO orbitals computed for the all Z-N'-(benzo(d)thiazol2-yl)-N,N-dimethylformimidamide and its complexes. For Z-N'-(benzo(d)thiazol-2-yl)-N,N-dimethylformimidamide compound the values of the energy of $\mathrm{HOMO}$ and LUMO are given in Table (8), the difference between $\mathrm{HOMO}$ and LUMO is 0.11586 for the free ligand, but in case of complexes the difference between HOMO and LUMO is 0.05134 for the first complex while in case of second complex 0.01782, the values of $\mathrm{HOMO}, \mathrm{LUMO} \mathrm{HOMO}^{-1}$, $\mathrm{HOMO}^{-2}, \mathrm{LUMO}^{+1}$ and $\mathrm{LUMO}^{+2}$ are given in Table (8).
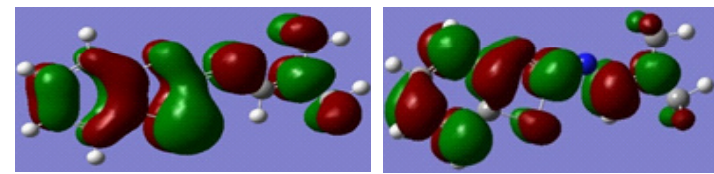

Z-N'-(benzo(d)thiazol-2-yl)-N,N-dimethylformimidamide
$\mathrm{HOMO}$

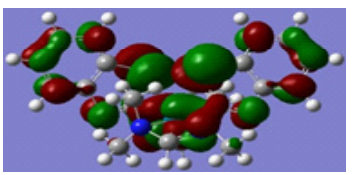

Fist complex

HOMO

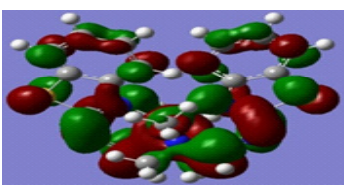

second complex

HOMO
LUMO

LUMO

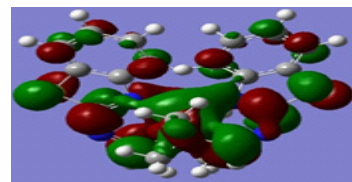

LUMO

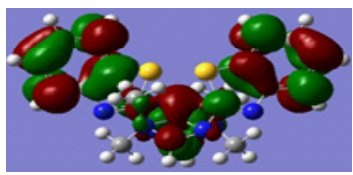

Fig. 6. Molecular orbital surfaces and energy levels of Z-N'-(benzo(d)thiazol-2-yl)-N,N-dimethylformimidamide and its two complexes by using B3LYP/Cep-31G 
Table 8: Values of energy (eV) of HOMO and LUMO for (A) Z-N'-(benzo(d)thiazol-2-yl)-N,N-dimethylformimidamide,

(B) first complex and (C) second complexby using B3LYP/Cep-31G

\begin{tabular}{cccc}
\hline & $(\mathrm{A})$ & $(\mathrm{B})$ & $(\mathrm{C})$ \\
\hline LUMO $^{+2}$ & -0.15619 & -0.18169 & -0.19091 \\
LUMO $^{+1}$ & -0.17839 & -0.19476 & -0.19233 \\
LUMO & -0.19618 & -0.19613 & -0.20865 \\
HOMO & -0.31204 & -0.24747 & -0.22647 \\
HOMO $^{-1}$ & -0.33211 & -0.25493 & -0.22792 \\
HOMO $^{-2}$ & -0.36322 & -0.25682 & -0.25851 \\
$\Delta \mathrm{E}=\mathrm{HOMO} \mathrm{-} \mathrm{LUMO}^{-0.11586}$ & 0.05134 & 0.01782 \\
\hline
\end{tabular}

\section{CONCLUSION}

The current method was utilized for the determination of palladium(II) in different water samples. The proposed procedures that involves coupling of BTDF as new reagent with palladium(II) for quantification of $\mathrm{Pd}(\mathrm{II})$ have some advantages such as selectivity, simplicity, stability and sensitivity as compared to many reported methods as provided in Table 4. Moreover, the methods is free from interference by different ions. The practical part are proved by theoretical studies.

\section{ACKNOWLEDGMENT}

This research did not receive any specific grant from funding agencies in the public, commercial, or not-for-profit sectors.

\section{REFERENCES}

1. Joule, J. A.; Mills, K.; Smith, G.F. Heterocyclic Chemistry, $3^{\text {rd }}$ ed., Chapman and Hall, London., 1995.

2. Davidson, J. P.; Faber, P. J.; Fischer, J. R.; Mansy, S.; Peresie, H. J.; Rosenberg, B.; VanCamp, L. Cancer Chemother. Rep., 1975, 59 (1), 287-300.

3. Barton, J.; Rabinowitz, H.; Szalda, D.; Lippard, S. J. Am. Chem. Soc., 1977, 99, 2827-2829.

4. Lippert, B. J. Clin. Hemat. Oncol., 1977, 7, 26-42.

5. Lippert, B. Inorg. Chem., 1981, 20, 43264343.

6. Chu, G.Y.H.; Duncan, R.E.; Tobias, R.S. Inorg. Chem., 1997, 36, 2625.

7. Lippert, B. in: Lippert B. (Ed.), Cisplatin, VHCA and Wiley-VCH, Zu"rich and Weinheim. 1999, 379-403.

8. Sakaguchi, S.; Kawakami, M.; O’Neill, J.; Yoo, K. S.; Jung, K. W. J. Organomet. Chem., 2010 , 695, 195-200.

9. Salas, J. M.; Romero, M. A.; Sánchez, M. P.; Quirós, M. Coord. Chem. Rev., 1999,193, 1119-1142.

10. Falvello, L.; Forniés, J.; Martin, A.; Navarro, R.; Sicilia, V.; Villarroya, P. Chem. Commun., 1998, 2429-2430.

11. Deacon, G. B.; Delbridge, E. E.; Forsyth, C. M.; Skelton, B. W.; White, A. H. J. Chem. Soc. Dalton Trans., 2000, 745-751.

12. Gust, K. R.; Knox, J. E.; Heeg, M. J.; Schlegel, H. B.; Winter, C. H. Angew. Chem. Int. Ed., 2002, 114, 1661-1664.
13. Deacon, G. B.; Forsyth, C. M.; Gitlits, A.; Harika, R.; Junk, P. C.; Skelton, B. W.; White, A. H. Angew. Chem. Int. Ed., 2002, 114, 33833385.

14. Perera, J. R.; Heeg, M. J.; Schlegel, H. B.; Winter, C. H. J. Am. Chem. Soc., 1999,121, 4536-4537.

15. (a) Lumme, P.; Mutikainen, I.; Lindell, E.Inorg. Chim. Acta., 1983, 71, 217-226.

(b) Goher, M. A.; Mautner, F. A.; Abu-Youssef, M. A. Transit Metal Chem., 1999, 24 (1), 29-34. (c) Sakai, K.; Tomita, Y.; Ue, T.; Goshima, K.; Ohminato, M.;Tsubomura, T.; Matsumoto, K.; Ohmura, K.; Kawakami, K.Inorg. Chim. Acta., 2000, 297, 64-71.

16. Okano, T.; Uekawa, T.; Morishima, N.; Eguchi, S. J. Org. Chem., 1991, 56, 5259-5262.

17. (a) Umada, A.;Okano, T.; Eguchi, S.Synthesis., 1994, 1457-1462. (b)Gerus, I.; Gorbunova, M.; Vdovenko, S.; Yagupol'skii, Y. L.; Kukhar', V. Chem. Inform., 1991, 22, 1878.

18. Plancquaert, M.A.; Redon, M.; Janousek, Z.; Viehe, H. G.Tetrahedron., 1996, 52, 43834396.

19. Tanaka, K.; Maeno, S.; Mitsuhashi, K. Heterocycl Chem., 1985, 22, 565-568.

20. Livshits, N.; Valiev, G.; Khasanov, S.; Kadyrov, C. S. Chem. Natural Compd., 1982, 18, 762763.

21. Britton, H. T. S. Hydrogen lons, fourth ed, Chapman and Hall, London., 1952, 113.

22. Ruhela, R.; Sharma, J.; Tomar, B.; Hubli, R.; Suri, A. Talanta., 2011, 85, 1217-1220. 
23. Frisch, M.; Trucks, G.; Schlegel, H.; Scuseria, G.; Robb, M.; Cheeseman, J.; Zakrzewski, V.; Montgomery Jr, J.; Stratmann, R.; Burant, Dapprich, J. S. Millam, J.M. Daniels, A.D. Kudin, K.N. Strain, M.C. Farkas, O Tomasi, J. Barone, V. Cossi, M. Cammi, R. Mennucci, B. Pomelli, C. Adamo, C. Clifford, S.Ochterski, Petersson, J. G. A. Ayala, P. Y. Cui, Q. Morokuma, K. Malick, D. K Rabuck, A.D. Raghavachari, K. Foresman, J.B. Cioslowski, J. Ortiz, J.V. Stefanov, B. B Liu, G. Liashenko, A. Piskorz, P. Komaromi, Gomperts,I. R.Martin, R. L. Fox, D. J. Keith, T. Al-Laham, M. A. Peng, C.Y. Nanayakkara, A. Gonzalez, C. Challacombe, M. P. Gill, M.W. Johnson, B. Chen, W. Wong, M. W. Andres, J. L. Gonzalez, C. Head-Gordon, M. Replogle, E. S. and Pople, J. A. Gaussian, revision A. 6; Gaussian, Inc. Pittsburgh, Pa., 1998, 40, 98.

24. Stevens, W. J.; Krauss, M.; Basch, H.; Jasien, P. G.Can. J. Chem., 1992, 70, 612-630.

25. Kohn, W.; Sham, L. J. Phys. Rev., 1965, 140, A1133.

26. Becke, A. D. Phys. Rev. A., 1988, 38, 3098.

27. Lee, C.; Yang, W.; Parr, R. G. Phys. Rev B., 1988, 37, 785.

28. Flurry R. L., Molecular Orbital Theory of Bonding in Organic Molecules, Marcel Dekker. New York., 1968.

29. (a) Masciocchi, N.; Moret, M.; Cairati, P.; Sironi, A.; Ardizzoia, G. A.; La Monica, G. J. J.O. T. A. C. S. J. Am. Chem. Soc., 1994, 116, 7668-7676. (b) Masciocchi, N.; Ardizzoia, G. A.; Maspero, A.; LaMonica, G.; Sironi, A.Inorg. Chem., 1999, 38, 3657-3664. (c) Ehlert, M.;
Rettig, S.; Storr, A.; Thompson, R.; Trotter, J. Can. J. Chem., 1989, 67, 1970-1974.(d) Murray, H.; Raptis, R. G.; Fackler Jr, J. P.Inorg. Chem., 1988, 27, 26-33.

30. Patent, Schenley Ind., US 2719161., 1952.

31. Turel, I.; Bukovec, P.; Quirós, M.Int. J. Pharm., 1997, 152, 59-65.

32. Sartorelli, A. C.; Agrawal, K. C.; Tsiftsoglou, A. S.; Moore, E. C.Adv. Enzyme Regul., 1977, 15, 117-139.

33. Ali, M. A.; Mirza, A. H.; Butcher, R. J.; Tarafder, M.; Keat, T. B.; Ali, A. M. J. Inorg. Biochem., 2002, 92, 141-148.

34. Xie, Y.-B.; Li, J.-R.; Zheng, Y.; Bu, X.-H.; Zhang, R.-H. J. Mol. Struct., 2003, 645, $227-$ 230.

35. Sakaguchi, S.; Kawakami, M.; O’Neill, J.;Yoo, K. S.; Jung, K.W. J. Organomet. Chem., 2010, 695, 195-200.

36. Chakraborty, J.; Saha, M. K.; Banerjee, P. Inorg. Chem. Commun., 2007, 10, 671-676.

37. Montoya, V.; Pons, J.; Garcia-Antón, J.; Solans, X.; Font-Bardia, M.; Ros, J. Inorganica Chim. Acta., 2007, 360, 625-637.

38. Serrano, J. L.; Garcıca, L.; Pérez, J.; Pérez, E.; Vives, J.; Sánchez, G.; López, G.; Molins, E.; Orpen, A. G.Polyhedron., 2007, 21, 1589-1596.

39. (a) Philp, D.; Stoddart, J. F.Angew. Chem., 1996, 35, 1154-1196.(b) Lehn, J.-M.; Sanders, J.Angew. Chem., 1995, 34, 2563.

40. Shen, L. L.; Hopper, D. C.; Wolfson, J. S. (Eds.), Quinolone Antimicrobial Agents, Second ed., A.S.M. Washington, DC., 1993, 77.

41. Fleming,I., Frontier Orbitals and Organic Chemical Reactions, Wiley, London., 1976. 